Article

\title{
Food Sources of Dietary Potassium in the Adult Japanese Population: The International Study of Macro-/Micronutrients and Blood Pressure (INTERMAP)
}

\author{
Nagako Okuda ${ }^{1, *(\mathbb{D}}$, Akira Okayama ${ }^{2} \mathbb{D}$, Katsuyuki Miura ${ }^{3,4}{ }^{\oplus}$, Katsushi Yoshita ${ }^{5}$, \\ Naoko Miyagawa ${ }^{6}$, Shigeyuki Saitoh ${ }^{7}$, Hideaki Nakagawa ${ }^{8}$, Kiyomi Sakata ${ }^{9}$, Queenie Chan ${ }^{10}$, \\ Paul Elliott ${ }^{10}$, Hirotsugu Ueshima ${ }^{3,4}$ and Jeremiah Stamler ${ }^{11}$ for the INTERMAP \\ Research Group \\ 1 Department of Health and Nutrition, University of Human Arts and Sciences, Saitama 339-8539, Japan \\ 2 Department of Non-Communicable Diseases, Research Institute of Strategy for Prevention, \\ Tokyo 104-0033, Japan; aokayama@jrisp.com \\ 3 Department of Public Health, Shiga University of Medical Science, Otsu 520-2192, Japan; \\ miura@belle.shiga-med.ac.jp (K.M.); hueshima@belle.shiga-med.ac.jp (H.U.) \\ 4 Center for Epidemiologic Research in Asia, Shiga University of Medical Science, Otsu 520-2192, Japan \\ 5 Department of Food Science and Nutrition, Graduate School of Human Life Science and Nutrition, \\ Osaka City University, Osaka 558-8585, Japan; yoshita@life.osaka-cu.ac.jp \\ 6 International Center for Nutrition and Information, National Institute of Biomedical Innovation, Health and \\ Nutrition, Tokyo 162-8636, Japan; naocom@belle.shiga-med.ac.jp \\ 7 School of Health Sciences, Sapporo Medical University, Sapporo 060-8556, Japan; ssaitoh@sapmed.ac.jp \\ 8 Medical Research Institute, Kanazawa Medical University, Kanazawa 920-0265, Japan; \\ hnakagaw@kanazawa-med.ac.jp \\ 9 Department of Hygiene and Public Health, Iwate Medical University, Yahaba 028-3694, Japan; \\ ksakata@iwate-med.ac.jp \\ 10 MRC-PHE Centre for Environment and Health, Department of Epidemiology and Biostatistics, \\ School of Public Health, Imperial College London, London SW7 2AZ, UK; q.chan@imperial.ac.uk (Q.C.); \\ p.elliott@imperial.ac.uk (P.E.) \\ 11 Feinberg School of Medicine, Northwestern University, Chicago, IL 60611, USA; j-stamler@northwestern.edu \\ * Correspondence: nagako_okuda@human.ac.jp; Tel.: +81-48-749-6111; Fax: +81-48-6110
}

Received: 17 February 2020; Accepted: 16 March 2020; Published: 17 March 2020

check for updates

\begin{abstract}
A lower-than-recommended potassium intake is a well-established risk factor for increased blood pressure. Although the Japanese diet is associated with higher sodium intake and lower potassium intake, few studies have examined the source foods quantitatively. Studies on dietary patterns in association with potassium intake will be useful to provide dietary advice to increase potassium intake. Twenty-four-hour (hr) dietary recall data and 24-hr urinary potassium excretion data from Japanese participants (574 men and 571 women) in the International Study of Macro/Micronutrients and Blood Pressure (INTERMAP) were used to calculate food sources of potassium and compare food consumption patterns among quartiles of participants categorized according to 24-hr urinary potassium excretion per unit of body weight (UK/BW). The average potassium intake was $2791 \mathrm{mg} /$ day per participant, and the major sources were vegetables and fruits (1262 mg/day), fish (333 mg/day), coffee and tea $(206 \mathrm{mg} /$ day), and milk and dairy products (200 mg/day). Participants in the higher UK/BW quartile consumed significantly more vegetables and fruits, fish, and milk and dairy products, and ate less rice and noodles. Conclusion: Advice to increase the intake of vegetables and fruits, fish, and milk may be useful to increase potassium intake in Japan.
\end{abstract}


Keywords: nutrition; potassium intake; 24-hr urine; 24-hr dietary recall; Japan; epidemiology

\section{Introduction}

Potassium is the most abundant cation in the human body, with $98 \%$ being intracellular and $2 \%$ being extracellular. Maintaining normal potassium homeostasis and the appropriate balance of potassium across the cell membrane is essential for cell function: particularly in excitable cells such as muscles and nerves [1]. Epidemiological and clinical studies revealed that a high-potassium diet reduced the blood puressure (BP) of individuals with hypertension and the average BP [2-4]. An association between a higher potassium intake and reduced cardiovascular disease (CVD) mortality was demonstrated in prospective cohort studies [3,4]. Based on these findings, the World Health Organization (WHO) recommended that healthy adults consume at least $3510 \mathrm{mg} /$ day of potassium in order to prevent increased BP and CVDs [5], while setting the salt (sodium chloride) reduction target for adults at less than $5 \mathrm{~g} /$ day [6]. In Japan, where more than $70 \%$ of the elderly population is hypertensive [7], the average daily salt intake level for adults was $9.9 \mathrm{~g}$ and that for potassium was $2279 \mathrm{mg}$ according to the National Health and Nutrition Survey Japan 2016 [7], demonstrating an unfavorable high-sodium and low-potassium pattern.

Vegetables and fruits have been thought to be major sources of potassium, and are often recommended in clinical and health education settings to prevent hypertension [8]. They are also recommended for those with impaired glucose tolerance or dyslipidemia because they are good sources of dietary fiber $[9,10]$. However, the effects of such education to encourage vegetable and fruit consumption are unclear. The National Health Nutrition Survey reported the declining trend in consumption of vegetables ( $279 \mathrm{~g} /$ day in 2001 to $265 \mathrm{~g} /$ day in 2016) and fruit (132 g/day to $99 \mathrm{~g} /$ day) [7]. Attention should be paid to other source foods of potassium because it exists in abundance in a wide variety of both animal products and vegetables, and studies on the actual food sources and dietary patterns of those with a lower/higher potassium intake in Japan are scarce. Studies on a high-potassium diet will be useful to create an effective dietary modification strategy to increase potassium intake.

The International Study of Macro/Micronutrients and Blood Pressure (INTERMAP) is an international cooperative study in Japan, the People's Republic of China, the United Kingdom, and the United States, in which detailed data on dietary intake were obtained from each participant through four 24-hr dietary recalls [11,12]. Two timed 24-hr urine collections were performed to assess urinary sodium and potassium excretion. Using the Japanese results collected between 1996 and 1998 (574 men and 571 women), we examined food intake patterns associated with 24-hr urinary sodium excretion, and found that people with higher sodium excretion ate more Japanese-style foods, including miso-soup, salted fish, and rice, and ate fewer Western foods, i.e., bread and milk [13]. In the present study, we investigate potassium source foods and evaluate differences in food consumption patterns among participants with a higher/lower potassium intake evaluated by 24-hr urinary potassium excretion per unit of body weight (UK/BW).

\section{Methods}

Detailed methods of the INTERMAP Study have been previously described [11,12]. Briefly, participants visited clinics four times on two consecutive days, approximately two to three weeks apart. Anthropometrics, BP measurements, and medical and lifestyle data were collected, including four in-depth 24-hr dietary recalls and two timed 24-hr urine specimens.

\subsection{Participants}

Participants were men and women aged 40 to 59 years recruited by four research centers in Japan. The four population samples were factory workers from Toyama in central Japan (149 men and 150 women), factory workers from Sapporo in northern Japan (149 men and 148 women), residents of 
Aito, a rural town in Shiga prefecture, central Japan (130 men and 129 men), and factory workers from Wakayama, central Japan (146 men and 144 women). The ethical committees of the Shiga University of Medical Science, Sapporo Medical University, Kanazawa Medical University, and Wakayama Medical University approved the study protocol. Written informed consent was received from all participants.

\subsection{Data Collection}

$\mathrm{BP}$ was measured eight times for each participant (twice at each of the four clinic visits) using a random zero sphygmomanometer by trained observers. Height and weight with light clothes were measured at each visit. Using a questionnaire, trained observers asked about lifestyles and the use of medications.

\subsection{Dietary Assessment}

Four in-depth 24-hr dietary recalls were conducted for each participant, one at each of the four visits, by specially trained dietary interviewers [12]. Prior to the data collection, in cooperation with the INTERMAP international nutritionist, a Japanese nutritionist supervising Japanese dietary data collection trained all interviewers and certified that they had sufficient skills to conduct dietary interviews and process dietary data. Standardized quality control procedures were utilized to ensure the quality of dietary data throughout data collection. Standardized sets of food models were used at all four research centers. In the 24-hr dietary recalls, participants were asked to report all the foods and beverages except for water consumed during the previous $24 \mathrm{hr}$. The INTERMAP Food Table Japan, an integrated food composition table based on the Standard Tables for Food Composition in Japan, 4th edition, was used to code foods and calculate nutrient intake [14]. Further details about the dietary surveys were described in previous reports. Averages of food and nutrient intakes obtained from four 24-hr recalls per participant were used in the analysis.

\subsection{Urine Collection, and Urinary Na and K Measurement}

Each participant provided two 24-hr urine collections, with start and end times recorded at the research center (at visits 1-2 and 3-4); measurements included urinary volume, $\mathrm{Na}, \mathrm{K}$, and creatinine. Eight percent of the urine samples were split locally and sent to the Central Laboratory for blinded estimation of technical error. Urinary values per $24-\mathrm{hr}$ were calculated as the product of urinary concentration and timed volume, standardized to $24 \mathrm{hr}$. Averages obtained from two 24-hr urine samples per participant were used in the analysis.

\subsection{Data Analysis}

To explore the association of food consumption with 24-hr urinary potassium excretion in the Japanese participants, 2508 food codes used in the dietary recalls were classified into 29 groups for this study (Table 1). For example, potassium is more abundant in muscle than in adipose tissue in animals; therefore, meat was categorized as "with visible fat" or "without visible fat". Fish was grouped according to total fat content; $<8 \%$ or $>=8 \%$. The average content of potassium and sodium $(\mathrm{mg} / 100 \mathrm{~g})$ for each food group was calculated as the total potassium amount divided by the total food amount consumed in all dietary recalls. Food (g) and potassium (mg) intakes per day and per $1000 \mathrm{kcal}$ of the 29 food groups were calculated for each participant. Calculations were also made for sodium. Subtotals for food categories (i.e., starchy foods, fish) were calculated.

The mean of the two 24-hr urinary potassium excretion values divided by body weight (UK/BW, $\mathrm{mmoL} / 24 \mathrm{hr} / \mathrm{kg}$ ) was calculated for each participant. Participants were divided into quartiles according to UK/BW, men, and women separately. Potassium intake from each of the 29 food groups (mg/1000 kcal) was compared among the quartiles of UK/BW, men, and women combined. We used the potassium excretion value adjusted by body weight in order to examine the characteristics of the food intake pattern by excluding the effects of the amount eaten or body size. 
All eight readings of systolic and diastolic BP (SBP and DBP) were used to calculate the average SBP/DBP of each participant. For height and weight, means of four measurements were used in the analyses. Body mass index (BMI) was calculated as weight $(\mathrm{kg})$ divided by the height squared $(\mathrm{m})$. The $p$-value was calculated to examine the linear relationship among the UK/BW quartiles, analyzed as a continuous variable. For categorical variables, the chi-squared test or Fisher's exact test was used. Two-tailed significance level was set at $p<0.05$. SPSS statistics version 21.0 (IBM Corporation, Tokyo, Japan) was used for all analyses.

\section{Results}

The food groups, their average potassium and sodium content, and the average daily intake from these foods are shown in Table 1. The average potassium content was high in both animal products ( $335 \mathrm{mg} / 100 \mathrm{~g}$ for fish, and $291 \mathrm{mg} / 100 \mathrm{~g}$ for meat), and vegetables and fruits $(262 \mathrm{mg} / 100 \mathrm{~g}$ ). Starchy foods had a low average potassium content $(35 \mathrm{mg} / 100 \mathrm{~g})$. The average total dietary potassium intake per participant estimated from the dietary survey was $2791 \mathrm{mg} /$ day. Major potassium source foods were vegetables and fruits (1262 mg/day of potassium), milk, beverages, sweets and snacks (561 mg/day), and fish (333 mg/day). The potassium content in salted foods (salted fish, cured meat, and salted vegetables) was similar to that in non-salted foods, but the sodium content was high and its intake from these foods was $1315 \mathrm{mg} /$ day and accounted for $28 \%$ of the total sodium intake.

Table 1. Twenty-nine food categories for investigation of the association of food group consumption with potassium $(\mathrm{K})$ intake.

\begin{tabular}{|c|c|c|c|c|c|}
\hline \multirow{3}{*}{ Food Group } & \multirow{3}{*}{$\begin{array}{c}\begin{array}{c}\text { Food Intake } \\
\text { (g/Day/Participant) }\end{array} \\
\text { Mean } \pm \text { SD }\end{array}$} & \multicolumn{2}{|c|}{$\begin{array}{l}\text { Average Content } \\
(\mathrm{mg} / 100 \mathrm{~g})\end{array}$} & \multicolumn{2}{|c|}{$\begin{array}{c}\text { Average Intake } \\
\text { (mg/Day/Participant) }\end{array}$} \\
\hline & & \multirow{2}{*}{ K } & \multirow{2}{*}{$\mathrm{Na}$} & K & $\mathrm{Na}$ \\
\hline & & & & Mean \pm SD & Mean \pm SD \\
\hline Starchy foods, total & $522 \pm 181$ & 35 & 57 & $182 \pm 60$ & $297 \pm 265$ \\
\hline Rice & $410 \pm 181$ & 28 & 2 & $113 \pm 50$ & $9 \pm 10$ \\
\hline Bread & $33 \pm 36$ & 100 & 523 & $33 \pm 37$ & $171 \pm 191$ \\
\hline Noodles without soup & $72 \pm 75$ & 37 & 146 & $26 \pm 33$ & $106 \pm 189$ \\
\hline Other cereals & $7 \pm 8$ & 132 & 163 & $10 \pm 12$ & $12 \pm 19$ \\
\hline Fish and fish products, total & $99 \pm 56$ & 335 & 799 & $333 \pm 201$ & $795 \pm 554$ \\
\hline Fish, fat $<8 \%$ (not salted) & $42 \pm 39$ & 373 & 248 & $155 \pm 142$ & $103 \pm 121$ \\
\hline Fish, fat $>=8 \%$ (not salted) & $18 \pm 19$ & 366 & 252 & $65 \pm 73$ & $45 \pm 89$ \\
\hline Salted fish & $40 \pm 29$ & 282 & 1613 & $113 \pm 100$ & $647 \pm 520$ \\
\hline Meat, meat products and eggs, total & $58 \pm 40$ & 291 & 392 & $168 \pm 111$ & $213 \pm 179$ \\
\hline Meat, without skin/visible fat & $20 \pm 27$ & 311 & 57 & $63 \pm 73$ & $12 \pm 18$ \\
\hline Meat, with skin/visible fat & $26 \pm 23$ & 307 & 59 & $78 \pm 72$ & $15 \pm 15$ \\
\hline Cured meat product & $12 \pm 16$ & 222 & 1089 & $27 \pm 34$ & $130 \pm 164$ \\
\hline $\begin{array}{l}\text { Other manufactured foods } \\
\text { (e.g., precooked hamburgers) }\end{array}$ & $15 \pm 24$ & 219 & 619 & $34 \pm 49$ & $95 \pm 157$ \\
\hline Eggs & $39 \pm 25$ & 118 & 147 & $46 \pm 29$ & $57 \pm 45$ \\
\hline Vegetable and fruits, total & $481 \pm 194$ & 262 & 131 & $1262 \pm 520$ & $628 \pm 489$ \\
\hline Vegetables & $230 \pm 97$ & 304 & 30 & $699 \pm 327$ & $70 \pm 98$ \\
\hline Salted vegetables (Japanese pickles) & $29 \pm 26$ & 310 & 1864 & $90 \pm 92$ & $538 \pm 471$ \\
\hline Potatoes & $49 \pm 39$ & 377 & 5 & $186 \pm 168$ & $2 \pm 2$ \\
\hline Soy beans, legumes and nuts & $60 \pm 51$ & 133 & 18 & $80 \pm 77$ & $11 \pm 22$ \\
\hline Fruits, fresh, dried and canned & $113 \pm 102$ & 159 & 6 & $206 \pm 190$ & $7 \pm 31$ \\
\hline Milk, beverages, and sweets and snacks, total & $1138 \pm 470$ & 49 & 18 & $561 \pm 251$ & $200 \pm 125$ \\
\hline Milk and dairy products & $126 \pm 117$ & 158 & 76 & $200 \pm 190$ & $96 \pm 87$ \\
\hline Fruit juice & $10 \pm 30$ & 183 & 6 & $9 \pm 34$ & $1 \pm 3$ \\
\hline Coffee, tea & $698 \pm 348$ & 93 & 3 & $205 \pm 122$ & $20 \pm 28$ \\
\hline Alcohol beverages & $233 \pm 335$ & 30 & 3 & $70 \pm 114$ & $7 \pm 10$ \\
\hline $\begin{array}{c}\text { Other beverages } \\
\text { (carbonated drinks and sports drinks) }\end{array}$ & $30 \pm 79$ & 51 & 43 & $15 \pm 44$ & $13 \pm 38$ \\
\hline Sweets and snacks & $40 \pm 35$ & 154 & 159 & $61 \pm 62$ & $64 \pm 69$ \\
\hline
\end{tabular}


Table 1. Cont.

\begin{tabular}{|c|c|c|c|c|c|}
\hline \multirow{3}{*}{ Food Group } & \multirow{3}{*}{$\begin{array}{c}\begin{array}{c}\text { Food Intake } \\
\text { (g/Day/Participant) }\end{array} \\
\text { Mean } \pm \text { SD }\end{array}$} & \multicolumn{2}{|c|}{$\begin{array}{l}\text { Average Content } \\
(\mathrm{mg} / \mathbf{1 0 0 g})\end{array}$} & \multicolumn{2}{|c|}{$\begin{array}{c}\text { Average Intake } \\
\text { (mg/Day/Participant) }\end{array}$} \\
\hline & & \multirow{2}{*}{$\mathbf{K}$} & \multirow{2}{*}{$\mathrm{Na}$} & $\mathbf{K}$ & $\mathrm{Na}$ \\
\hline & & & & Mean \pm SD & Mean \pm SD \\
\hline Soup and condiments, total & $244 \pm 109$ & 84 & 992 & $206 \pm 93$ & $2426 \pm 782$ \\
\hline Miso soup & $127 \pm 89$ & 59 & 340 & $74 \pm 70$ & $431 \pm 301$ \\
\hline Soup for noodles & $45 \pm 53$ & 44 & 546 & $20 \pm 26$ & $247 \pm 305$ \\
\hline $\begin{array}{l}\text { Salty condiments and spices } \\
\text { (e.g., soy sauce, salt, dressings) }\end{array}$ & $49 \pm 30$ & 224 & 3558 & $109 \pm 58$ & $1736 \pm 642$ \\
\hline Sugar and sweeteners & $12 \pm 7$ & 15 & 1 & $2 \pm 8$ & $0 \pm 0$ \\
\hline Fats and oils & $12 \pm 7$ & 6 & 95 & $1 \pm 1$ & $11 \pm 24$ \\
\hline TOTAL & $2597 \pm 601$ & & & $2791 \pm 701$ & $4650 \pm 1279$ \\
\hline
\end{tabular}

Characteristics of participants according to UK/BW quartiles are shown in Table 2. For both men and women, the mean age was significantly higher and average BMI was significantly lower in the higher quartile. There was no significant difference in drinking habits among quartiles. Fewer current smokers were found in the higher UK/BW quartile among men, but not among women. Few participants reported following vegetarian or reduced salt diets, and there were no significant differences among quartiles. We found no significant differences in the use of medications for hypertension, diabetes mellitus, or lipid disorders among UK/BW quartiles. The average SBP and DBP were significantly lower in the higher quartile in both men and women.

Table 2. Characteristics of participants stratified by quartiles of 24-hr urinary potassium (K) excretion per unit of body weight (mmoL/24 hr/kg, UK/BW), men and women, ages 40-59.

\begin{tabular}{|c|c|c|c|c|c|}
\hline & Q1 & Q2 & Q3 & Q4 & $P$ \\
\hline & Mean \pm SD & Mean \pm SD & Mean \pm SD & Mean \pm SD & \\
\hline \multicolumn{6}{|l|}{ Men } \\
\hline $\mathrm{n}$ & 143 & 144 & 144 & 143 & \\
\hline Age (year) & $49.2 \pm 5.8$ & $48.8 \pm 5$ & $49.7 \pm 5.1$ & $50.4 \pm 5.2$ & 0.02 \\
\hline Body mass index $\left(\mathrm{kg} / \mathrm{m}^{2}\right)$ & $24.4 \pm 2.9$ & $24.1 \pm 2.7$ & $23.6 \pm 2.7$ & $22.8 \pm 2.3$ & $<0.01$ \\
\hline \multicolumn{6}{|l|}{ Drinking habits, n (\%) } \\
\hline Current drinker & $138(96.5)$ & $139(96.5)$ & $140(97.2)$ & $141(98.6)$ & 0.59 \\
\hline Ex-drinker & $0(0)$ & $2(1.4)$ & $1(0.7)$ & $1(0.7)$ & \\
\hline Non-drinker & $5(3.5)$ & $3(2.1)$ & $3(2.1)$ & $1(0.7)$ & \\
\hline \multicolumn{6}{|l|}{ Smoking habits, n (\%) } \\
\hline Current smoker & $82(57.3)$ & $79(54.9)$ & $69(47.9)$ & $67(46.9)$ & 0.006 \\
\hline Ex-smoker & $44(30.8)$ & $29(20.1)$ & $37(25.7)$ & $34(23.8)$ & \\
\hline Non-smoker & 17 (11.9) & $36(25)$ & $38(26.4)$ & $42(29.4)$ & \\
\hline On vegetarian diet, n (\%) & $0(0)$ & $1(0.7)$ & $2(1.4)$ & $0(0)$ & 0.62 \\
\hline On reduced salt diet, n (\%) & $4(2.8)$ & $1(0.7)$ & $4(2.8)$ & $5(3.5)$ & 0.27 \\
\hline \multicolumn{6}{|l|}{ Use of medication, $\mathrm{n}(\%)$} \\
\hline Hypertension & $13(9.1)$ & $10(6.9)$ & $6(4.2)$ & $5(3.5)$ & 0.16 \\
\hline Diabetes mellitus & $1(0.7)$ & $3(2.1)$ & $2(1.4)$ & $4(2.8)$ & 0.16 \\
\hline Lipid disorder & $4(2.8)$ & $3(2.1)$ & $3(2.1)$ & $8(5.6)$ & 0.12 \\
\hline SBP (mmHg) & $123.2 \pm 13.1$ & $120.2 \pm 12.9$ & $119.5 \pm 12.6$ & $118.7 \pm 12.7$ & 0.003 \\
\hline DBP (mmHg) & $78.8 \pm 10.4$ & $77.2 \pm 9.9$ & $76.3 \pm 8.7$ & $74.9 \pm 10.6$ & 0.001 \\
\hline
\end{tabular}


Table 2. Cont.

\begin{tabular}{cccccc}
\hline & Q1 & Q2 & Q3 & Q4 & P \\
\cline { 2 - 5 } & Mean \pm SD & Mean \pm SD & Mean \pm SD & Mean \pm SD & \\
Women & & & & & \\
n & 142 & 143 & 143 & 143 & \\
Age (year) & $48.3 \pm 5.4$ & $48.9 \pm 5.2$ & $48.9 \pm 5.2$ & $50.7 \pm 5.2$ & $<0.001$ \\
Body mass index (kg/m $\left.{ }^{2}\right)$ & $24.4 \pm 3.4$ & $23.5 \pm 3$ & $22.7 \pm 3$ & $22.1 \pm 2.3$ & $<0.001$ \\
Drinking habits, $\mathrm{n}(\%)$ & & & & & \\
Current drinker & $117(82.4)$ & $118(82.5)$ & $126(88.1)$ & $120(83.9)$ & 0.38 \\
Ex-drinker & $4(2.8)$ & $5(3.5)$ & $4(2.8)$ & $9(6.3)$ & \\
Non-drinker & $21(14.8)$ & $20(14)$ & $13(9.1)$ & $14(9.8)$ & \\
Smoking habits, $\mathrm{n}(\%)$ & & & & & \\
Current smoker & $18(12.7)$ & $14(9.8)$ & $8(5.6)$ & $9(6.3)$ & 0.31 \\
Ex-smoker & $3(2.1)$ & $3(2.1)$ & $5(3.5)$ & $2(1.4)$ & \\
Non-smoker & $121(85.2)$ & $126(88.1)$ & $130(90.9)$ & $132(92.3)$ & \\
On vegetarian diet, $\mathrm{n}(\%)$ & $1(0.7)$ & $2(1.4)$ & $1(0.7)$ & $2(1.4)$ & 1.00 \\
On reduced salt diet, $\mathrm{n}(\%)$ & $2(1.4)$ & $9(6.3)$ & $6(4.2)$ & $5(3.5)$ & 0.32 \\
Use of medication, $\mathrm{n}(\%)$ & & & & & \\
Hypertension & $13(9.2)$ & $8(5.6)$ & $9(6.3)$ & $7(4.9)$ & 0.11 \\
Diabetes mellitus & $2(1.4)$ & $2(1.4)$ & $4(2.8)$ & $0(0)$ & 0.32 \\
Lipid disorder & $6(4.2)$ & $4(2.8)$ & $4(2.8)$ & $5(3.5)$ & 0.87 \\
SBP (mmHg) & $115.5 \pm 13.9$ & $115.2 \pm 14.9$ & $113.4 \pm 13.2$ & $112.2 \pm 13.5$ & 0.026 \\
DBP (mmHg) & $71.5 \pm 10.4$ & $71.2 \pm 9.7$ & $69.8 \pm 9.2$ & $69.2 \pm 9$ & 0.021 \\
\hline
\end{tabular}

$P$-values, obtained from trend analysis or chi-squared tests. SBP, systolic blood pressure; DBP, diastolic blood pressure.

Urinary excretion of potassium and sodium according to quartiles of UK/BW are shown in Table 3. In total, 24-hr urinary potassium excretion level was higher in women than in men, but sodium excretion and urinary $\mathrm{Na} / \mathrm{K}$ ratio was higher in men. Although $24-\mathrm{hr}$ urinary sodium excretion was moderately higher in the higher quartile, the urinary sodium to potassium ratio was significantly lower in the higher quartile due to significantly higher potassium excretion.

Table 3. Electrolyte excretion from 24-hr urine of participants stratified by quartiles of 24-hr urinary potassium excretion per unit of body weight (mmoL/24 hr/kg, UK/BW), men and women, ages 40-59.

\begin{tabular}{cccccc}
\hline & Q1 & Q2 & Q3 & Q4 & \multirow{2}{*}{ Trend $\boldsymbol{P}$} \\
\cline { 2 - 5 } & Mean \pm SD & Mean \pm SD & Mean \pm SD & Mean \pm SD & \\
\hline Men & & & & & \\
K per body weight $(\mathrm{mmoL} / 24 \mathrm{hr} / \mathrm{kg})$ & $0.52 \pm 0.07$ & $0.67 \pm 0.03$ & $0.78 \pm 0.03$ & $1.00 \pm 0.17$ & $<0.001$ \\
$\mathrm{~K}(\mathrm{mmoL} / 24 \mathrm{hr})$ & $36.1 \pm 6.6$ & $45.3 \pm 6.6$ & $52 \pm 7.1$ & $63.6 \pm 13.2$ & $<0.001$ \\
Na per body weight $(\mathrm{mmoL} / 24 \mathrm{hr} / \mathrm{kg})$ & $2.74 \pm 0.71$ & $3.09 \pm 0.71$ & $3.3 \pm 0.67$ & $3.54 \pm 0.93$ & $<0.001$ \\
$\mathrm{Na}(\mathrm{mmoL} / 24 \mathrm{hr})$ & $188.3 \pm 51.4$ & $208.7 \pm 52.3$ & $220.6 \pm 52.1$ & $224.5 \pm 63.3$ & $<0.001$ \\
$\mathrm{Na} / \mathrm{K}(\mathrm{mmoL} / \mathrm{mmol})$ & $5.33 \pm 1.43$ & $4.67 \pm 1.11$ & $4.3 \pm 0.9$ & $3.61 \pm 0.94$ & $<0.001$ \\
Women & & & & \\
$\mathrm{K}$ per body weight $(\mathrm{mmoL} / 24 \mathrm{hr} / \mathrm{kg})$ & $0.59 \pm 0.08$ & $0.77 \pm 0.05$ & $0.94 \pm 0.05$ & $1.24 \pm 0.19$ & $<0.001$ \\
$\mathrm{~K}(\mathrm{mmoL} / 24 \mathrm{hr})$ & $34.5 \pm 6.3$ & $43.2 \pm 6.5$ & $50.9 \pm 7.4$ & $65.3 \pm 11.2$ & $<0.001$ \\
$\mathrm{Na}$ per body weight $(\mathrm{mmoL} / 24 \mathrm{hr} / \mathrm{kg})$ & $2.82 \pm 0.79$ & $3.36 \pm 0.74$ & $3.56 \pm 0.86$ & $3.76 \pm 0.98$ & $<0.001$ \\
$\mathrm{Na}(\mathrm{mmoL} / 24 \mathrm{hr})$ & $166.5 \pm 54.7$ & $187.8 \pm 49.4$ & $192.5 \pm 51.6$ & $197.1 \pm 51.9$ & $<0.001$ \\
$\mathrm{Na} / \mathrm{K}(\mathrm{mmoL} / \mathrm{mmoL})$ & $4.91 \pm 1.3$ & $4.4 \pm 1$ & $3.84 \pm 0.9$ & $3.11 \pm 0.87$ & $<0.001$ \\
\hline
\end{tabular}

The potassium intake per $1000 \mathrm{kcal}$ of total energy intake from food groups with participants stratified by UK/BW quartiles is shown in Table 4. The potassium intake from vegetables and fruits, fish, milk, and miso soup was significantly higher in the higher quartiles. Coffee and tea were a source of potassium (102 mg/1000 kcal) equivalent to fruits $(107 \mathrm{mg} / 1000 \mathrm{kcal})$ or milk (102 mg/1000 kcal), but there was no significant difference in potassium contribution among quartiles. 
Table 4. Potassium intake (mg/1000 kcal) from 29 food groups, participants stratified by quartiles of 24-hr urinary potassium excretion per unit of body weight (mmoL/24 hr/kg, UK/BW), men and women, ages $40-59$.

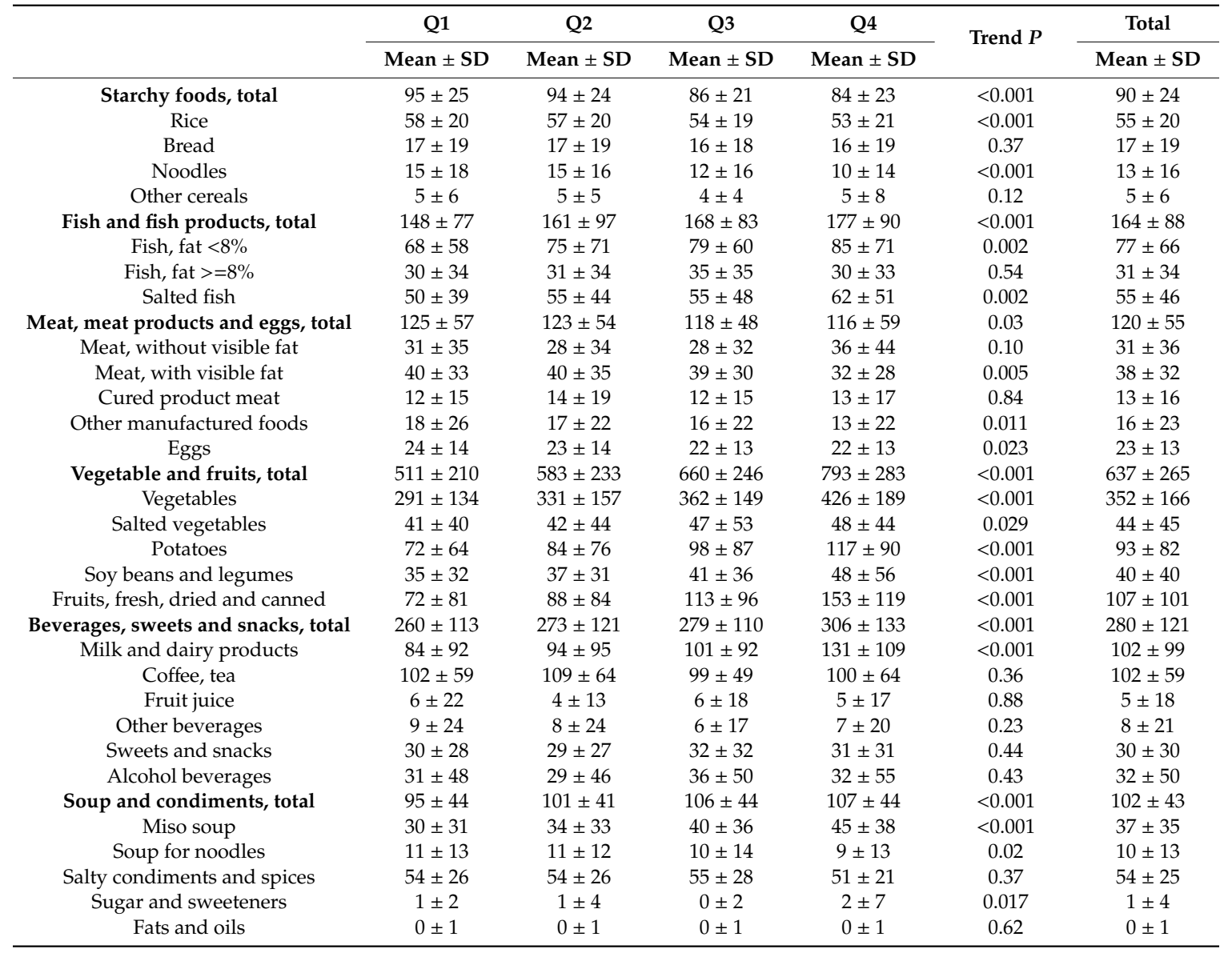

\section{Discussion}

We examined dietary patterns associated with 24-hr urinary potassium excretion using data from the detailed dietary survey in the INTERMAP Japan Study, and quantitatively demonstrated the relationship between food intake and potassium excretion. To the best of our knowledge, this is the first study in which participants were categorized according to 24-hr urinary potassium excretion and potassium intake from detailed food groups was compared. Major potassium source foods were vegetables and fruits, fish, and milk. Consumption of these foods was higher in the participants with higher potassium excretion. Potassium from vegetables and fruits accounted for almost half of the daily potassium intake.

One study in Spain found a higher vegetable and fruit intake in the higher 24-hr urinary potassium excretion group, but the potassium intake from these foods was not presented [15]. Previously, we used results from the National Health and Nutrition Survey Japan in 1980 and 1990, and compared food intakes among those with a higher/lower potassium intake estimated from household-based semi-weighed dietary records [16]. The food intake pattern associated with a higher potassium intake was similar to that in the present study, i.e., lower intake from cereals, and higher intake from vegetables, fruits, fish, and milk and dairy products. A recent study in Poland used Household Budget Survey data, and reported vegetables, meat and meat products, and cereal products to be the major potassium source foods [17]. 
In this study, participants with a lower UK/BW consumed more rice and noodles and had a higher 24-hr urinary $\mathrm{Na} / \mathrm{K}$ ratio. Dietary habits of having more simple meals, such as noodles or rice bowl dishes, may lead to low potassium intake. Conversely, those with a higher UK/BW consumed more vegetables, fruits, and fish. Fish and vegetables often require a longer cooking process than meat. People with a higher potassium intake may have eaten vegetables and fish habitually by taking time and effort in food preparation. For those with lower potassium intake, an economical and effortless eating style, e.g., pre-cut fruit or vegetables, may be useful to improve their consumption.

Some other foods to increase the potassium intake should be recommended to prevent hypertension and CVDs. Studies have reported a lower prevalence of hypertension and CVD mortality among people with higher milk consumption $[18,19]$. Although the prevalence of lactose intolerance is reported to be as high as $90 \%$ in Asian populations [20], there are few symptomatic individuals with moderate milk consumption. The percentage of milk wasted from elementary school lunch was $8.5 \%$ [21], and $28 \%$ of adults reported having abdominal symptoms after drinking milk [22]. Milk may be a good source of potassium for those without abdominal symptoms because it is generally low-energy and requires no additional sodium.

Another option may be the use of condiments with potassium-enriched salt, which may reduce sodium intake and improve the dietary $\mathrm{Na} / \mathrm{K}$ ratio [23-25]. The major source of sodium in Japan is soy sauce, which we previously reported to account for $806 \mathrm{mg}$ of the daily sodium intake [13]. Habitual use of potassium-enriched soy sauce, miso, and other prepared foods will be useful for sodium reduction and potassium increase, without advising people to improve their diet. Participants in an intervention study using potassium-enriched condiments in Japan successfully used these condiments at home while cooking and their urinary $\mathrm{Na} / \mathrm{K}$ ratio decreased significantly [25]. Coffee and tea are infusions of coffee beans or tea leaves, respectively, and provide an amount of potassium ( $205 \mathrm{mg} /$ day) nearly equal to that of one serving of vegetable dish. Potassium intake from fruit juice, other beverages (carbonated drinks and sports drinks), alcoholic beverages, and sweets and snacks was small. These foods were not good sources of potassium. Excess consumption of these foods, including ultra-processed foods, may lead to obesity and related outcomes through a higher energy intake [26].

The average SBP and DBP were significantly lower in the higher UK/BW quartile. Although previous studies have reported lower BP levels in people with a higher potassium intake [2,4], our results may be related to the lower average BMI in the higher UK/BW quartile. They consumed more vegetables, fruits, and fish, and ate less starchy foods and meat. These dietary patterns with a higher intake of low-energy-density foods may have led to the overall lower BMI level.

Our study had several strengths. Highly standardized procedures were adopted for 24-hr dietary recall surveys in the INTERMAP Study, and we obtained highly detailed food and beverage consumption data of individual participants. Thus, we were able to evaluate potassium source foods quantitatively, including coffee and tea, which are often excluded in dietary surveys. In addition, 24-hr urine was collected during the period of the 24-hr recall survey; a large portion of the potassium intake during the 2nd and 4th 24-hr dietary recalls should have been excreted into the 1st and 2nd 24-hr urine samples, respectively. The correlation coefficient between dietary and urinary estimates of potassium in this survey was 0.565 [9], and the dietary data were assumed to be sufficient to examine the food intake factors associated with the difference in urinary potassium excretion. One limitation of our study is that the data were collected from 1996 to 1998, and dietary habits may have changed, specifically the increase in eating-out and use of prepared foods. To examine the current status of potassium intake, further studies using an extended food database that covers foods served in restaurants and prepared foods should be performed.

In summary, people with a higher dietary potassium intake consumed more vegetables, fruits, fish, and milk, and ate less rice and noodles in Japan. Advice to increase the intake of vegetables, fruits, fish, and milk may be useful to increase potassium intake. 
Author Contributions: Conceptualization, N.O. and A.O.; Methodology, N.O. and K.M.; Formal Analysis, N.O.; Investigation, A.O., S.S., H.N., K.M., K.S., K.Y., and N.O.; Data Curation, Q.C., P.E., and N.O.; Writing-Original Draft Preparation, N.O.; Writing-Review and Editing, N.O., K.M., N.M., K.Y., A.O., Q.C., and J.S.; Project Administration, J.S., P.E., H.U., and A.O.; Funding Acquisition, J.S., P.E., H.U., A.O., S.S., H.N., and K.S. All authors have read and agreed to the published version of the manuscript.

Funding: This study was funded by grant 2-RO1-HL50490 and R01-HL135486 from the US National Heart, Lung, and Blood Institute, National Institutes of Health, Bethesda, Maryland, and by national and local agencies in China, Japan (the Ministry of Education, Science, Sports, and Culture, Grant-in-Aid for Scientific Research [A], No. 090357003, JSPS KAKENHI Grant Number 26460759), and the United Kingdom. P.E. is a Senior Investigator of the UK National Institute of Health Research (NIHR) and is supported by the NIHR, the Imperial College Healthcare NHS Trust and Imperial College Biomedical Research Centre. P.E. is also supported by the UK MRC-PHE Centre for Environment and Health and the UK NIHR Health Protection Research Unit on Health Impacts of Environmental Hazards. This study was also supported in part by the Japan Dairy Association.

Conflicts of Interest: N.O. and A.O. received a research grant from the Japan Dairy Association. The funders had no role in the design of the study; in the collection, analyses, or interpretation of data; in the writing of the manuscript, or in the decision to publish the results.

\section{References}

1. Kovesdy, C.P.; Appel, L.J.; Grams, M.E.; Gutekunst, L.; McCullough, P.A.; Palmer, B.F.; Pitt, B.; Sica, D.A.; Townsend, R.R. Potassium Homeostasis in Health and Disease: A Scientific Workshop Cosponsored by the National Kidney Foundation and the American Society of Hypertension. Am. J. Kidney Dis. 2017, 70, 844-858. [CrossRef]

2. INTERSALT Cooperative Research Group. INTERSALT: An international study of electrolyte excretion and blood pressure. Results for 24 hour urinary sodium and potassium excretion. INTERSALT Cooperative Research Group. BMJ 1988, 297, 319-328.

3. Chang, H.Y.; Hu, Y.W.; Yue, C.S.; Wen, Y.W.; Yeh, W.T.; Hsu, L.S.; Tsai, S.Y.; Pan, W.H. Effect of potassium-enriched salt on cardiovascular mortality and medical expenses of elderly men. Am. J. Clin. Nutr. 2006, 83, 1289-1296. [CrossRef] [PubMed]

4. He, F.J.; MacGregor, G.A. Beneficial effects of potassium on human health. Physiol. Plant. 2008, 133, 725-735. [CrossRef] [PubMed]

5. WHO. Guideline: Potassium Intake for Adults and Children. Available online: http://www.who.int/nutrition/ publications/guidelines/potassium_intake/en/ (accessed on 13 February 2020).

6. WHO. Guideline: Sodium Intake for Adults and Children. Available online: http://www.who.int/nutrition/ publications/guidelines/sodium_intake/en/index.html (accessed on 3 March 2020).

7. Ministry of Health, Labour and Welfare. National Health and Nutrition Survey Japan 2016. Available online: http://www.mhlw.go.jp/bunya/kenkou/eiyou/h28-houkoku.html (accessed on 13 February 2020). (In Japanese)

8. Japan Hypertension Society. Guidelines for the Management of Hypertension 2019; Life Science Publishing: Tokyo, Japan, 2019. (In Japanese)

9. Anderson, J.W.; Baird, P.; Davis, R.H., Jr.; Ferreri, S.; Knudtson, M.; Koraym, A.; Waters, V.; Williams, C.L. Health benefits of dietary fiber. Nutr. Rev. 2009, 67, 188-205. [CrossRef]

10. Li, M.; Fan, Y.; Zhang, X.; Hou, W.; Tang, Z. Fruit and vegetable intake and risk of type 2 diabetes mellitus: Meta-analysis of prospective cohort studies. BMJ Open 2014, 4, e005497. [CrossRef]

11. Stamler, J.; Elliott, P.; Dennis, B.; Dyer, A.R.; Kesteloot, H.; Liu, K.; Ueshima, H.; Zhou, B.F. INTERMAP: Background, aims, design, methods, and descriptive statistics (nondietary). J. Hum. Hypertens 2003, 17, 591-608. [CrossRef]

12. Dennis, B.; Stamler, J.; Buzzard, M.; Conway, R.; Elliott, P.; Moag-Stahlberg, A.; Okayama, A.; Okuda, N.; Robertson, C.; Robinson, F.; et al. INTERMAP: The dietary data-process and quality control. J. Hum. Hypertens 2003, 17, 609-622. [CrossRef]

13. Okuda, N.; Okayama, A.; Miura, K.; Yoshita, K.; Saito, S.; Nakagawa, H.; Sakata, K.; Miyagawa, N.; Chan, Q.; Elliott, P.; et al. Food sources of dietary sodium in the Japanese adult population: The international study of macro-/micronutrients and blood pressure (INTERMAP). Eur. J. Nutr. 2017, 56, 1269-1280. [CrossRef] 
14. Schakel, S.F.; Dennis, B.H.; Wold, A.C.; Conway, R.; Zhao, L.; Okuda, N.; Okayama, A.; Moag-Stahlberg, A.; Robertsoni, C.; Van Heel, N.; et al. Enhancing data on nutrient composition of foods eaten by participants in the INTERMAP Study in China, Japan, the United Kingdom, and the United States. J. Food Compos. Anal. 2003, 16, 395-408. [CrossRef]

15. Rodriguez-Rodriguez, E.; Ortega, R.M.; Andres Carvajales, P.; Gonzalez-Rodriguez, L.G. Relationship between $24 \mathrm{~h}$ urinary potassium and diet quality in the adult Spanish population. Public Health Nutr. 2015, 18, 850-859. [CrossRef] [PubMed]

16. Turin, T.C.; Okuda, N.; Miura, K.; Nakamura, Y.; Rumana, N.; Ueshima, H.; Group, N.D.R. Dietary intake of potassium and associated dietary factors among representative samples of Japanese general population: NIPPON DATA 80/90. J. Epidemiol. 2010, 20 (Suppl. 3), S567-S575. [CrossRef] [PubMed]

17. Gorska-Warsewicz, H.; Rejman, K.; Laskowski, W.; Kowalcze, K. Food Sources of Potassium in the Average Polish Diet. Nutrients 2019, 11, 2905. [CrossRef]

18. Ralston, R.A.; Lee, J.H.; Truby, H.; Palermo, C.E.; Walker, K.Z. A systematic review and meta-analysis of elevated blood pressure and consumption of dairy foods. J. Hum. Hypertens 2012, 26, 3-13. [CrossRef] [PubMed]

19. Alexander, D.D.; Bylsma, L.C.; Vargas, A.J.; Cohen, S.S.; Doucette, A.; Mohamed, M.; Irvin, S.R.; Miller, P.E.; Watson, H.; Fryzek, J.P. Dairy consumption and CVD: A systematic review and meta-analysis. Br. J. Nutr. 2016, 115, 737-750. [CrossRef] [PubMed]

20. Silanikove, N.; Leitner, G.; Merin, U. The Interrelationships between Lactose Intolerance and the Modern Dairy Industry: Global Perspectives in Evolutional and Historical Backgrounds. Nutrients 2015, 7, 7312-7331. [CrossRef]

21. Kojima, Y.; Abe, A.; Abe, K.; Akamatsu, R. The relationship between food waste from school lunches and nutrient intake in elementary school children. Jpn. J. Nutr. Diet 2013, 71, 86-93. (In Japanese) [CrossRef]

22. Sasaki, J. Intestinal lactase activity in Japanese adults. Jpn. J. Gastroenterol. 1972, 68, 37-49. (In Japanese)

23. Okayama, A.; Okuda, N.; Miura, K.; Okamura, T.; Hayakawa, T.; Akasaka, H.; Ohnishi, H.; Saitoh, S.; Arai, Y.; Kiyohara, Y.; et al. Dietary sodium-to-potassium ratio as a risk factor for stroke, cardiovascular disease and all-cause mortality in Japan: The NIPPON DATA80 cohort study. BMJ Open 2016, 6, e011632. [CrossRef]

24. Greer, R.C.; Marklund, M.; Anderson, C.A.M.; Cobb, L.K.; Dalcin, A.T.; Henry, M.; Appel, L.J. Potassium-Enriched Salt Substitutes as a Means to Lower Blood Pressure: Benefits and Risks. Hypertension 2020, 75, 266-274. [CrossRef]

25. Okuda, N.; Miura, M.; Itai, K.; Morikawa, T.; Sasaki, J.; Asanuma, T.; Fujii, M.; Okayama, A. Use of Lightly Potassium-Enriched Soy Sauce at Home Reduced Urinary Sodium-to-Potassium Ratio. J. Food Nutr. Sci. 2019, 1, 27-36. [CrossRef]

26. Monteiro, C.A.; Moubarac, J.C.; Levy, R.B.; Canella, D.S.; Louzada, M.; Cannon, G. Household availability of ultra-processed foods and obesity in nineteen European countries. Public Health Nutr. 2018, 21, 18-26. [CrossRef] [PubMed]

(C) 2020 by the authors. Licensee MDPI, Basel, Switzerland. This article is an open access article distributed under the terms and conditions of the Creative Commons Attribution (CC BY) license (http://creativecommons.org/licenses/by/4.0/). 